\title{
Recruiting at Campus Job Fairs: Matching Candidate to Individual Industry Requirements
}

\author{
Jana Minifie \\ Texas State University \\ James Bell \\ Texas State University \\ Yi Zhang \\ Texas State University \\ Author Note
}

Jana Minifie, Texas State University, Management

James Bell, Texas State University, Management

Yi Zhang, Texas State University, Management

Correspondence concerning this article should be directed to: jm13@txstate.edu

\begin{abstract}
On-campus job fairs can often be the first point of contact between college students and employment recruiters. As such, this research examines if recruiters from different industries use the same criteria for selecting candidates for further review and interviews. Specifically, this study surveyed recruiters from five different job fairs representing commercial (business, industry, and construction), non-profit, government, and school districts and identifies recruiter reported preferences in evaluating and selecting candidates for hire. Our findings identify variations in recruiter preferences related to résumés, GPA, references, communication skills, personality traits, ethics, and intelligence.
\end{abstract}

Key Words: Employee Hiring; Campus Recruiting; Industry Recruiting

\section{Introduction}

For more than forty years, extensive research has been conducted regarding employee selection and employee hiring. Previous research has generally been focused on recommendations in the areas of résumé writing, GPA, references, interviewing, evaluating personality factors, job requirements, and legal issues to name a few. However, most reported findings and recommendations have been generic and not industry specific. 
For many universities, the career services office sponsors on-campus career job fairs as both a service and an opportunity for students to meet with several prospective employers. At many of these events, an average of 25 hiring organizations participates as well as an average of 400 job seekers (nationalcareerfairs.com/exhibitors, 7/3/14). Effective career job fairs offer the potential of matching prospective employers with current and previously enrolled students in that university.

Research has shown the emphasis companies place on recruiting new employees via job fairs; however, when employers are asked what they are looking for in a new hire, the literature does not distinguish between various industries. The problem, then, becomes the fact that many on-campus career services prepare students for job fairs by recommending generic strategies related to the résumé (Brennan \& Mattice, 2015; Cole et.al, 2007; Frankel, 2016; LiveCareer.com 10/20/16), character traits and personality (Verschoor, 2016; Beshara, 2011; Smith-Barrow, 2013; Zopiatis \& Constanti, 2012; Yang, Gong, \& Huo, 2011), preparation (Beshara, 2011; Smith-Barrow, 2013), and does not focus on the varying criteria among different kinds of industries (Wilson, 2006). This research effort examines whether these generic strategies are applicable across different industries.

\section{Research Relevance}

The previous research generalized results to all organizations and did not examine possible differences between recruiters representing different organizations and industry type. Thus, this study separates and distinguishes recruiter preferences across employer type: commercial (business, industry, and construction); non-profits; government agencies; and school districts. This research assesses and compares recruiter responses and preferences from different employment sectors related to selecting candidates for interviews and hiring.

\section{Methodology: Survey and Analysis}

Using previous research as a guideline, we constructed a draft survey for recruiters and had the content validated by a Human Resource professor not associated with the study. Our survey was then critiqued by a Director of Career Services and a pilot was tested by five recruiters not associated with the current study. Next, the University Institutional Research Group reviewed and approved the survey. This 77-question survey was given to recruiters at five job fairs at a large university $(30,000+$ student enrollment) in the southern region of the United States.

This research details the survey content, the sample, the analysis used, reports findings, discusses those findings, details study limitations, and ends with recommendations for future research.

\section{Survey Content}

The Recruiters Survey consisted of 77 questions divided into five sections. Section 1 contained 21 questions and evaluated recruiters preferences related to the résumé, GPA, work experience, references, job interviews, and general interview related items. Section 2, (47 questions) assessed intelligence and GPA, personality related items, and character related items. 
Section 3 (4 questions) inquired as to what assessments and tests are administered in recruiter firms. Section 4 included five demographic questions. Except for "fill-ins" and demographic questions, a seven-point scale was used: "Strongly Disagree, Moderately Disagree, Slightly Disagree, Neither Disagree Nor Agree, Slightly Agree, Moderately Agree, and Strongly Agree." Respondents were given instructions such as: "When selecting a finalist for the job, please use the scale below and write the number that matches your level of agreement or disagreement." Example questions included:

- "The résumé is an important criterion in selecting a candidate."

- "Previous work experience is an important criterion in selecting a candidate."

- "Performance in the job interview is an important criterion in selecting a candidate."

- "My organization purposefully seeks to employ people...who have high aspirations."

Other résumé questions included overall GPA, GPA in major, outside extra-curricular activities, work/internship experience, class, work projects and samples, and references, all common items found on a student résumé.

\section{Job Fair Sample}

Over four months, recruiters from five different job fairs were sampled. Specifically, 375 recruiters were asked to complete the survey, and 169 completed surveys that answered all questions (45\% response rate) (See Table 1 ).

Table 1

Job Fairs Selected for Analysis

Job Fair Companies

Summer Job Fair: Non-Profits

Spring Construction Job Fair

Spring Job \& Internship Fair: Business \& Industry

Spring Government Job Fair

Spring Teacher Job Fair
60 companies, 67 recruiters

25 companies, 30 recruiters

130 companies, 130 recruiters

25 companies, 21 recruiters*

135 school districts, 129 recruiters*

Note: * Indicates that some firms provided literature but sent no personal representative to the respective job fair.

Surveys were distributed to Job Fair recruiters during registration and were returned at the close of the fair. Recruiters were kept anonymous and assured that all questions were voluntary. Of the respondents, 64 were male, 95 female; 10 did not list a gender. Of those who identified their race, 106 listed white, 10 listed African American, 33 listed Hispanic, 1 listed Asian, 3 listed Mixed and 1 'other'. The average tenure with their organization was 7.9 years, 
and the average full-time experience of the recruiters surveyed was 16.1 years. Of 157 recruiters answering the question regarding the extent they were engage in the overall recruiting effort, 79.6\% stated that they "Moderately Agree" or "Strongly Agree" that they are "Fully involved in the recruiting process," while 77.9\% stated they "Moderately Agree" or "Strongly Agree" that they are "Fully involved in the interviewing process."

\section{Analysis}

As noted, to assess if differences between recruiter preferences existed, recruiters from five job fairs were surveyed. Data as analyzed using SPSS. Recruiters represented commercial organizations (business, industry, or construction) were labeled COM; government, GOV; nonprofit, NP; and Independent School Districts, ISD.

\section{Results}

\section{General Candidate Selection}

In analyzing the individual questions between job fairs, responses to fourteen questions identified significant differences between Non-Profit (NP), Government (GOV), Commercial (COM), and Independent School Districts (ISD). We begin with general results, specific significance differences in recruiting groups, and results related to Big Five Personality preferences. Hiring groups were analyzed separately and what follows identifies significant differences between groups (See Table 2).

The results provide insight into what criteria these different organizations look for in terms of a candidate. Non-Profits place more emphasis on enthusiasm than the other categories and less emphasis on GPA. Since NPs seek to persuade others to support their cause, it would follow that they would place more emphasis on enthusiasm than the other industries.

Government recruiters were significantly lowest on several criteria to include both verbal and non-verbal communication skills, enthusiasm, positive attitude, and compatibility with organizational culture. Business recruiters were highest for organizational culture fit and nonverbal communication skills. They were significantly lower with providing strong references and the accuracy of résumé content. Independent School Districts placed significantly higher emphasis on GPA, providing strong references, the accuracy of résumé, verbal skills, and positive attitude. 
Table 2

Recruiter Variances by Industry

\begin{tabular}{|c|c|c|c|c|c|}
\hline Question & $\begin{array}{l}\text { Sector } \\
1 \\
\end{array}$ & $\begin{array}{l}\text { Sector } \\
2\end{array}$ & $\begin{array}{l}\text { Mean } \\
\text { Difference }\end{array}$ & $\begin{array}{l}\text { Std. } \\
\text { Error }\end{array}$ & Significance \\
\hline $\begin{array}{l}\text { GPA in the college major is an } \\
\text { important criterion for selecting a } \\
\text { candidate }\end{array}$ & ISD & NP & 1.317 & .371 & .003 \\
\hline \multirow{3}{*}{$\begin{array}{l}\text { Providing strong references is an } \\
\text { important criterion for selecting a } \\
\text { candidate }\end{array}$} & \multirow[t]{3}{*}{$\mathrm{COM}$} & GOV & -1.195 & .277 & .000 \\
\hline & & ISD & -1.929 & .224 & .000 \\
\hline & & $\mathrm{NP}$ & -1.094 & .282 & .001 \\
\hline \multirow{2}{*}{$\begin{array}{l}\text { Our organization contacts references } \\
\text { and asks questions to determine the } \\
\text { 'accuracy' of information listed on a } \\
\text { candidate's résumé }\end{array}$} & \multirow[t]{2}{*}{$\mathrm{COM}$} & GOV & -1.269 & .354 & .002 \\
\hline & & ISD & -1.586 & .286 & .000 \\
\hline \multirow{2}{*}{$\begin{array}{l}\text { Non-verbal communication skills (eye } \\
\text { contact, handshake, etc.) are important } \\
\text { criterions in selecting a candidate }\end{array}$} & COM & GOV & 0.779 & .178 & .000 \\
\hline & GOV & ISD & -7.39 & .190 & .001 \\
\hline \multirow{2}{*}{$\begin{array}{l}\text { Verbal skills are an important criterion } \\
\text { for selecting a candidate }\end{array}$} & COM & GOV & 0.811 & .182 & .000 \\
\hline & GOV & ISD & -0.814 & .194 & .000 \\
\hline \multirow{3}{*}{$\begin{array}{l}\text { Enthusiasm is an important criterion for } \\
\text { selecting a candidate }\end{array}$} & COM & GOV & 0.685 & .154 & .000 \\
\hline & GOV & ISD & -0.664 & .164 & .000 \\
\hline & $\mathrm{NP}$ & GOV & 0.694 & .190 & .002 \\
\hline \multirow{2}{*}{$\begin{array}{l}\text { A positive attitude is a very important } \\
\text { criterion for selecting a candidate. }\end{array}$} & COM & GOV & 0.674 & .163 & .000 \\
\hline & GOV & ISD & -0.694 & .174 & .001 \\
\hline \multirow{2}{*}{$\begin{array}{l}\text { Our organization evaluates and looks } \\
\text { for compatibility of the person with our } \\
\text { organizations' culture }\end{array}$} & COM & GOV & 1.001 & .213 & .000 \\
\hline & GOV & ISD & -7.69 & .228 & .005 \\
\hline
\end{tabular}

NOTE: COM: Commercial recruiter; ISD: Independent School District recruiter; GOV: Government recruiter; NP: Non-Profit recruiter

\section{Big 5 Personality Traits}

When Big 5 personality categories were assessed, responses from six individual questions differed between Job Fair Recruiters. Table 3 shows the between group ANOVA for all Big 5 personality traits. Only three of the three Big 5 personality traits that showed statistically difference between groups were: Openness, Agreeableness, and Extraversion. Table 4 shows the one-way ANOVA for those questions, which were statistically significant between groups.

Results from specific recruiting sectors were as follows: Non-Profit recruiters did not seek candidates who were competitive; however, non-profits responses were similar to other recruiter groups in other Big Five preferences. 
Table 3

Big 5 Personality One-Way Analysis of Variance

\begin{tabular}{l|l|r|r|r|r|c}
\hline \multicolumn{2}{l}{} & $\begin{array}{r}\text { Sum of } \\
\text { Squares }\end{array}$ & \multicolumn{1}{c|}{ df } & $\begin{array}{c}\text { Mean } \\
\text { Square }\end{array}$ & \multicolumn{1}{c}{ F } & Sig. \\
\hline Neuroticism & Between Groups & 5.368 & 3 & 1.789 & 2.827 & .040 \\
& Within Groups & 99.993 & 158 & .633 & & \\
& Total & 105.361 & 161 & & & \\
\hline Extraversion & Between Groups & 13.915 & 3 & 4.638 & 9.386 & .000 \\
& Within Groups & 64.239 & 130 & .494 & & \\
& Total & 78.153 & 133 & & & \\
\hline Openness & Between Groups & 12.271 & 3 & 4.090 & 7.857 & .000 \\
& Within Groups & 81.214 & 156 & .521 & & \\
& Total & 93.485 & 159 & & & \\
\hline Agreeableness & Between Groups & 4.446 & 3 & 1.482 & 3.492 & .017 \\
& Within Groups & 65.775 & 155 & .424 & & \\
& Total & 70.221 & 158 & & & \\
\hline Conscientiousness & Between Groups & 1.497 & 3 & .499 & 1.624 & .186 \\
& Within Groups & 47.627 & 155 & .307 & & \\
& Total & 49.124 & 158 & & & \\
\hline
\end{tabular}

Government recruiters reported not valuing openness related to trying new things, being intellectually curious, entertaining novel ideas, as well as extraversion as it relates to having high aspirations.

For agreeableness, Commercial recruiter responses were significantly different from other recruiters and reported a low concern for being cooperative and giving others a chance. COM groups did place a higher emphasis on extraversion traits of competitiveness and having high aspirations.

ISD recruiters were highest on openness - try new things and activities, being intellectually curious, and entertaining novel ideas, and agreeableness - being cooperative/giving others a chance.

To further assess personality preferences representing neuroticism and extraversion, two survey questions were "open-ended" and required recruiters to select the "most important item" the recruiter and organization values. Furthermore, the recruiter was asked to share how the recruiter and organization determine if the candidate possesses this quality. T-tests were performed for questions 32, neuroticism, and question 39, extraversion.

A limitation of the survey was that it did not ask for a ranking for openness, agreeableness, or conscientiousness, as doing so would have required respondents to rank 22 preferences. 
Table 4

Big 5 Personality One-Way Analysis

\begin{tabular}{|c|c|c|c|c|c|}
\hline Question & Sector & Sector & $\begin{array}{c}\text { Mean } \\
\text { Difference }\end{array}$ & $\begin{array}{l}\text { Std. } \\
\text { Error }\end{array}$ & Significance \\
\hline \multicolumn{6}{|l|}{ Openness } \\
\hline Seeks people who are willing to try & $\mathrm{COM}$ & ISD & -0.590 & .173 & .004 \\
\hline new things and activities & GOV & ISD & -0.838 & .232 & .002 \\
\hline $\begin{array}{l}\text { Seeks people who are intellectually } \\
\text { curious }\end{array}$ & GOV & ISD & -8.610 & .244 & .003 \\
\hline $\begin{array}{l}\text { Seeks people who entertain novel } \\
\text { ideas }\end{array}$ & $\mathrm{COM}$ & ISD & -0.717 & .186 & .001 \\
\hline \multicolumn{6}{|l|}{ Agreeableness } \\
\hline $\begin{array}{l}\text { Seeks people who are } \\
\text { cooperative/give others a chance }\end{array}$ & $\mathrm{COM}$ & ISD & -0.680 & .173 & .001 \\
\hline \multicolumn{6}{|l|}{ Extraversion } \\
\hline Seeks people who are competitive & NP & COM & -1.014 & .271 & .001 \\
\hline $\begin{array}{l}\text { Seeks people who have high } \\
\text { aspirations }\end{array}$ & $\mathrm{COM}$ & GOV & 0.732 & .200 & .002 \\
\hline
\end{tabular}

\section{Neuroticism}

Six statements were used to assess neuroticism.

My organization sees to employ people:

Q26: who are calm under stress.

Q27: who have coping skills.

Q28: who control impulses.

Q29: who control their emotions.

Q30: who don't get easily discouraged.

Q31: who are sensitive.

Open-ended questions:

Q32a: From the previous list (26 to 31), please write the number of the item your organization values most.

32b. How do you determine if the candidate has this?

All groups provided similarly and statistically non-significant answers for neuroticism questions (see Table 5). However, 66.7\% of GOV recruiters valued trait 30 and preferred applicants who are not easily discouraged. ISD's recruiters reported valuing applicants who have coping skills, (27\%), while COM valued those who are calm under stress $(37.8 \%)$. 
When asked to list how recruiters assessed neuroticism, all reported using interview methods and background checks.

Table 5

Measure Recruiters Used To Evaluate Neuroticism

\begin{tabular}{ll}
\hline Group & P-VALUE \\
\hline GOV-ISD & 0.2554 \\
GOV-NP & 0.2799 \\
GOV-COM & 0.0659 \\
ISD-NP & 0.838 \\
ISD-COM & 0.2967 \\
NP-COM & 0.6567 \\
\hline
\end{tabular}

\section{Extraversion}

Extraversion was assessed in a similar way by asking recruiters to select the item they and the organization most values.

My organization seeks to employ people:

Q33: who are optimistic.

Q34: who form attachments to others - fit in.

Q35: who prefer other people's company.

Q36: who are energetic.

Q37: who crave excitement.

Q38: who are independent versus a follower.

Once again, recruiters were asked two open-ended questions (39 a \& b) as was done with neuroticism (See Table 6).

Table 6

Measure Recruiters Used To Evaluate Extraversion

\begin{tabular}{ll}
\hline Group & P-VALUE \\
\hline GOV-ISD & 0.01487 \\
GOV-NP & 0.08862 \\
GOV-COM & 0.7707 \\
ISD-NP & 0.5285 \\
ISD-COM & 0.0001868 \\
NP-COM & 0.0512 \\
\hline
\end{tabular}

Results indicated that all groups preferred optimistic and energetic candidates. COM preferred independent and energetic candidates more than GOV did. ISDs seek optimistic candidates $(50 \%)$ with $25 \%$ choosing energetic as the second highest preference. COM recruiters are almost equal in preferring optimistic, energetic, and independent candidates $(28.24 \%$, $28.24 \%$, and $25.88 \%$ ). Recruiters from all groups again reported assessing personality traits using interview methods and background checks. 


\section{Personality Results Discussion}

Analysis indicates that government recruiters are looking for individuals who are less extraverted and prefer to keep to a routine. They seem to look for people who follow standard operating procedures. All recruiters seek a match between the expectations of the job with the candidates' preferences. Business recruiters, as well, are looking for candidates that fit their culture of being in a dynamically changing environment.

Independent School Districts are looking for candidates who demonstrate a high level of Openness and Agreeableness but are perhaps placing these individuals into a much-regulated environment often driven by test results on state exams. Inappropriate job placement might explain the high turnover rate for the ISD industry as a whole. In other words, ISDs may not match their recruiting preferences with the realities of the job.

Related to using standardized methods of assessing candidates, the survey asked if organizations administered personality tests, ethical/integrity tests, intelligence tests, and other types of assessments.

Q65: My organization administers the Myers-Briggs Test.

Q66: My organization administers an Ethical or Integrity Test.

Q67: My organization administers tests of intelligence.

Q68: My organization administers other types of assessments. If yes to Q68, which assessments do you use?

T-tests were also performed for questions 65-67: 65: Myers-Briggs Personality Preference, 66: Ethical and Integrity Tests, and 67: Tests of Intelligence (See Table 7).

Responses from GOV, ISD, and NP indicate that these sectors do not typically administer these tests. However, $25 \%, 28 \%$, and $25 \%$ of COM administer personality, ethics/integrity, and intelligence tests. Question 68 asked if the organization administers other types of assessments, and, if answered yes, we asked which assessments were used.

Table 7

Recruiters Indicated That They Used Standardized Assessments Of Candidates

\begin{tabular}{lccr}
\hline & \multicolumn{3}{c}{ P-Value } \\
\cline { 2 - 4 } \multicolumn{1}{c}{ Groups } & $\begin{array}{c}\text { Myers- } \\
\text { Briggs }\end{array}$ & $\begin{array}{c}\text { Ethical or } \\
\text { Integrity } \\
\text { Tests }\end{array}$ & $\begin{array}{c}\text { Intelligence } \\
\text { Tests }\end{array}$ \\
\hline GOV-ISD & 0.5298 & 0.1239 & 0.5298 \\
GOV-NP & 0.9097 & 0.2513 & 0.3322 \\
GOV-COM & 0.0987 & 0.5493 & 0.1218 \\
ISD-NP & 0.5709 & 0.5709 & 0.322 \\
ISD-COM & 0.0003 & $<0.0001$ & 0.00051 \\
NP-COM & 0.0477 & 0.00572 & $<0.0001$ \\
\hline
\end{tabular}


Recruiters mostly from business (COM) reported their firms administered the following types of assessments: DISC Profile, Target Assessment, Kenexa, BPAD, KRAFT Questions, Sales Index, Bennett Mechanical, 16PF, and job specific testing done by an occupational therapist. Non-profits and ISDF's reported conducting background tests and checking with references.

Although previous research indicates that General Mental Ability (GMA) can account for up to one-third of performance for management jobs and up to 16 percent in semi-skilled positions (Tracey, quoting Hunter, 1986, p. 316), very few recruiters, mostly those representing businesses, reported assessing GMA.

\section{Major Findings}

As the study reported, multiple responses from recruiters representing various industries differed. For example, non-profit recruiters placed a higher emphasis on enthusiasm than did other groups. This finding is intuitively obvious as non-profit jobs are focused on motivating volunteers, building relationships with donors, and searching for potential grants. It follows that non-profit recruiters would value the importance of enthusiasm as it is important in developing interpersonal relationships. In contrast, business recruiters reported seeking individuals who are competitive, have high aspirations, and perhaps seek to compete and 'climb the corporate ladder'.

Differing from both of non-profits and business recruiters, government and often education recruiters reported looking for employees who are not competitive or have high career aspirations. Non-competitiveness might be valued since, often, these employees are required to follow standard rules and regulations. Selecting employees who are less competitive may lead to success in these types of positions. Additionally, educational recruiters reported seeking employees who wanted to try new things, were intellectually curious, entertained novel ideas, were cooperative, and would give others a chance.

As the results indicate, recruiters in multiple areas seek different types of employees and evaluate candidates differently. Noting that different industries 'ideal' recruit varies depending on the position needs, perhaps campus career center personnel should reevaluate how they prepare students for on-campus job fairs. Specifically, organizers of campus fairs should consider providing specific recommendations tailored to the perceived recruiter preferences representing specific industries and organizations. Thus, the typical generic recommendations at many career fairs should be modified to emphasize the needs of each industry to ensure students' success in their future employment. To do so, additional research needs to be conducted to identify and further test guidelines required for career service centers to tailor recommendations to specific hiring groups.

\section{Study Limitations}

The research was conducted in the southwestern part of the U.S. and findings are confined to one geographical area and may not be representative of all recruiters. Additionally, 
fifty percent of recruiters represented state-wide and local firms while the other recruiters represented national firms, both public and private. The results may be different when firms representing different geographical areas of the U.S. are surveyed.

The survey focused on neuroticism and extraversion but did not ask recruiters preferences related to openness, agreeableness, and conscientious. Future research may wish to study these in more depth by asking recruiters to identify which specific quality of each is valued most and how the recruiter and organization determines if one has this quality. Perhaps recruiters could be interviewed to assess how one learns of this quality in interviews or when conducting background checks.

Lastly, only 21 recruiters representing government responded compared to 40 from nonprofits, 40 from school districts, and 68 from business and construction. Perhaps it can be inferred that the lower number of government responders impacted results.

\section{Recommendation for Future Research}

This research is only a beginning of an examination of recruiter preferences of candidates at job fairs. Future research could examine how effective job fairs are at recruiting successful candidates for the position both from the college/career service perspective as well as the company's perspective. Also, recruiters might be asked the following: What are the expectations of companies at the job fair? Are companies at the job fair there to hire or to assess the quality of the applicant pool? Is there a ROI related to costs and benefits received? How many people are hired at job fairs? How do the hires compare with hiring at non-campus and traditional methods? How much decision-making power is given to the recruiter at the job fair? How are job fair representatives selected (personality, university affiliation, HR position in the company)? Also, future research needs to look at job fairs in terms of the prospective candidates: Why do they go to the job fair? Do they expect to get hired from the job fair? What do they think of the recruiters? Did the job fair change their perception of the company? What was their perception related to the recruiter based upon the recruiters perceived professionalism and skill? And lastly, what guidelines should career centers provide students in preparing for the appropriate career fair?

In addition, since character qualities (i.e. honesty, respect, accountability, cooperation, etc.) are being "taught and emphasized" in U.S. elementary, middle, and high schools, and ethics is being emphasized and taught in colleges and organizations, recruiters should be surveyed as to their specific character quality and ethics hiring preferences.

Based on the results that we received, we would recommend allowing recruiters to select "Does Not Apply" should a question not be appropriate for their company and/or industry.

Lastly, future research should examine if there is a relationship between the type of candidate that is being selected and the job description, as well as the relationship between the candidate's personality and the organization culture. For agreeableness, Commercial (COM) recruiter responses were significantly different from other recruiters and reported a low concern 
Job Fair: Candidate Industry Matching

for being cooperative and giving others a chance. COM groups did place a higher emphasis on extraversion traits of competitiveness and having high aspirations. 
Job Fair: Candidate Industry Matching

\section{References}

Beshara, T. (2011). Unbeatable Resumes--America's Top Recruiter Reveals What Really Gets You Hired. AMACO.

Brennan, J., \& Mattice, L. (2015). Resumes - still a critical document for the job search. Security, 52(8), 20. Retrieved from http://libproxy.txstate.edu/login?url=http://search.proquest.com.libproxy.txstate.edu/docv iew/1706202876? accountid=5683

Career Thought Leader Consortium, http://www.quintcareers.com/resume_length.html as viewed on July 3, 2014.

Cole, M. S., Rubin, R. S., Field, H. S., \& Giles, W. F. (2007). Recruiters' perceptions and use of applicant resume information: Screening the recent graduate. Applied Psychology: An International Review, 56, 319-343.

Frankel, C. (2016) Résumé writing in the digital age. Veterinary Team Brief. Retrieved from http://www.veterinaryteambrief.com/sites/default/files/attachments/Resume\%20Writing \%20in\%20the\%20Digital\%20Age_0.pdf

Live Career (LiveCareer.com), (2016) The scoop on resume length: How many pages should your resume be?, https://www.livecareer.com/quintessential/resume-length, as viewed on October 20, 2016.

National Association of College and Employers (NACEweb.org), (2014). 2013-2014 Career Service Benchmarks Survey for College and Universities. http://www.naceweb.org/uploadedFiles/Content/staticassets/downloads/executive-summary/2013-14-career-services-benchmarks-survey.pdf as viewed on August 12, 2014.

National Association of Colleges and Employers (NACEweb.org), (2014) Cost Per Hire Benchmark, http://www.naceweb.org/s05012013/cost-per-hire-benchmark.aspx as viewed on July 3, 2014.

National Association of Colleges and Employers (NACEweb.org), (2014) Branding Your Organization on Campus, http://www.naceweb.org/s01082014/branding-yourorganization-on-campus.aspx as viewed on July 3, 2014.

National Association of College and Employers (NACEweb.org), (2016) The Class of 2015 Student Survey Report, http://www.naceweb.org/surveys/student.aspx as viewed on October 19, 2016.

National Career Fairs, Exhibitor Information (nationalcareerfairs.com/exhibitors), (2014), http://nationalcareerfiars.com/exhibitors as viewed on October 19, 2016.

Smith-Barrow, D. (2013, 09). 4 ways to prepare to impress MBA recruiters. U.S. News \& World Report, 1.

Tracey, J. B., Sturman, M. C., \& Tews, M. J., (2007). Ability versus Personality: Factors that predict employee job performance. Cornell Hotel and Restaurant Administration Quarterly, 48(3) 313-322.

Verschoor, C. C, C.M.A., C.P.A. (2016). Hiring ethical employees. Strategic Finance, 98(1), 1718.

Wilson, M. (2006). What recruiters look for in on-campus interviews. The Black Collegian, 37(1), 33-36.

Yang, J., Gong, Y., \& Huo, Y. (2011). Proactive personality, social capital, helping and turnover intentions. Journal of Managerial Psychology, 26(8), 739-760. 
Job Fair: Candidate Industry Matching

Zopiatis, A., \& Constanti, P. (2012). Extraversion, openness and conscientiousness. Leadership \& Organization Development Journal, 33(1), 86-104. 